\title{
Development of a Sand Boil Testing Laboratory and Preliminary Results
}

By Isaac J. Stephens, Bryant A. Robbins, and Andrew M. Keffer

PURPOSE: To document the purpose, use, and preliminary results of a full-scale sand boil generator developed at the Geotechnical and Structures Laboratory.

BACKGROUND AND INTRODUCTION: Researchers at the U.S. Army Engineer Research and Development Center (ERDC) are developing innovative approaches and tools to improve existing flood-fighting techniques. The phrase "flood fighting" as used in this article refers to emergency operations and efforts that take place during flood events to reduce the risk of levee failure. One of the major risk drivers is backward erosion piping (BEP), a type of internal erosion that causes open erosion channels to progress through foundation sands beneath levees, creating sand boils as shown in Figure 1. In an attempt to control the erosion process, sand boils are often ringed with sandbags (Figure 2) or covered with barrels to raise the water level in the boil. By raising the water level, the horizontal hydraulic gradient in the foundation is reduced, and the erosion process will slow down, potentially stopping altogether.

Although sandbags have successfully been used to control BEP for decades, the use of sandbags is labor-intensive. ERDC research on sand boils is focused on developing alternative flood-fighting measures that are less labor-intensive than placing sandbags, yet equally as effective. As part of product testing and development, a sand boil laboratory has been developed that generates full-scale sand boils in a controlled setting. Efforts are currently underway to evaluate alternative flood-fighting measures using this laboratory. This technical note describes some of the preliminary efforts and results.

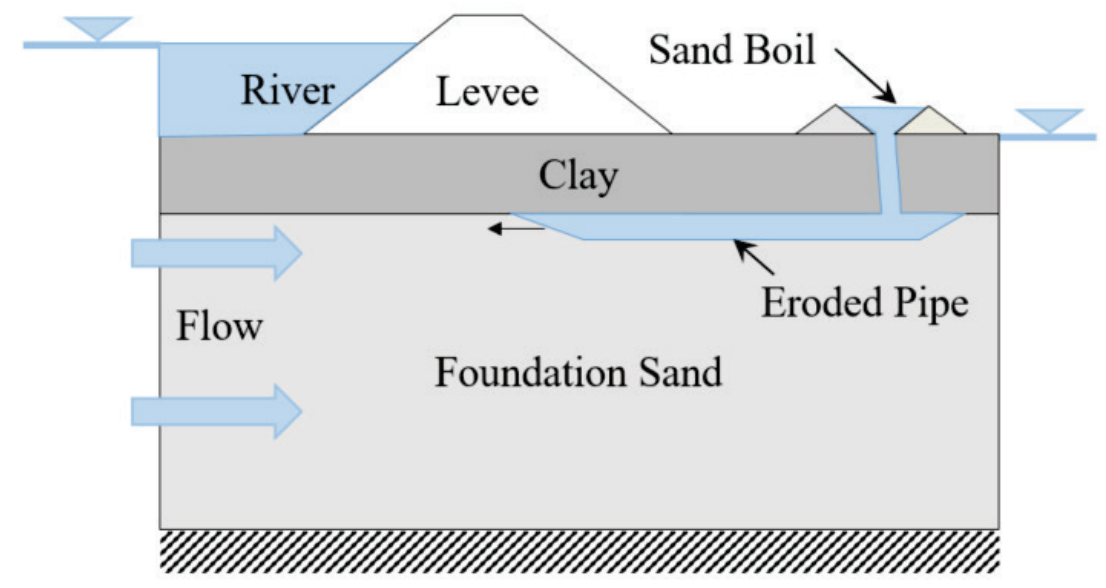

Figure 1. Illustration of backward erosion piping beneath a levee. 


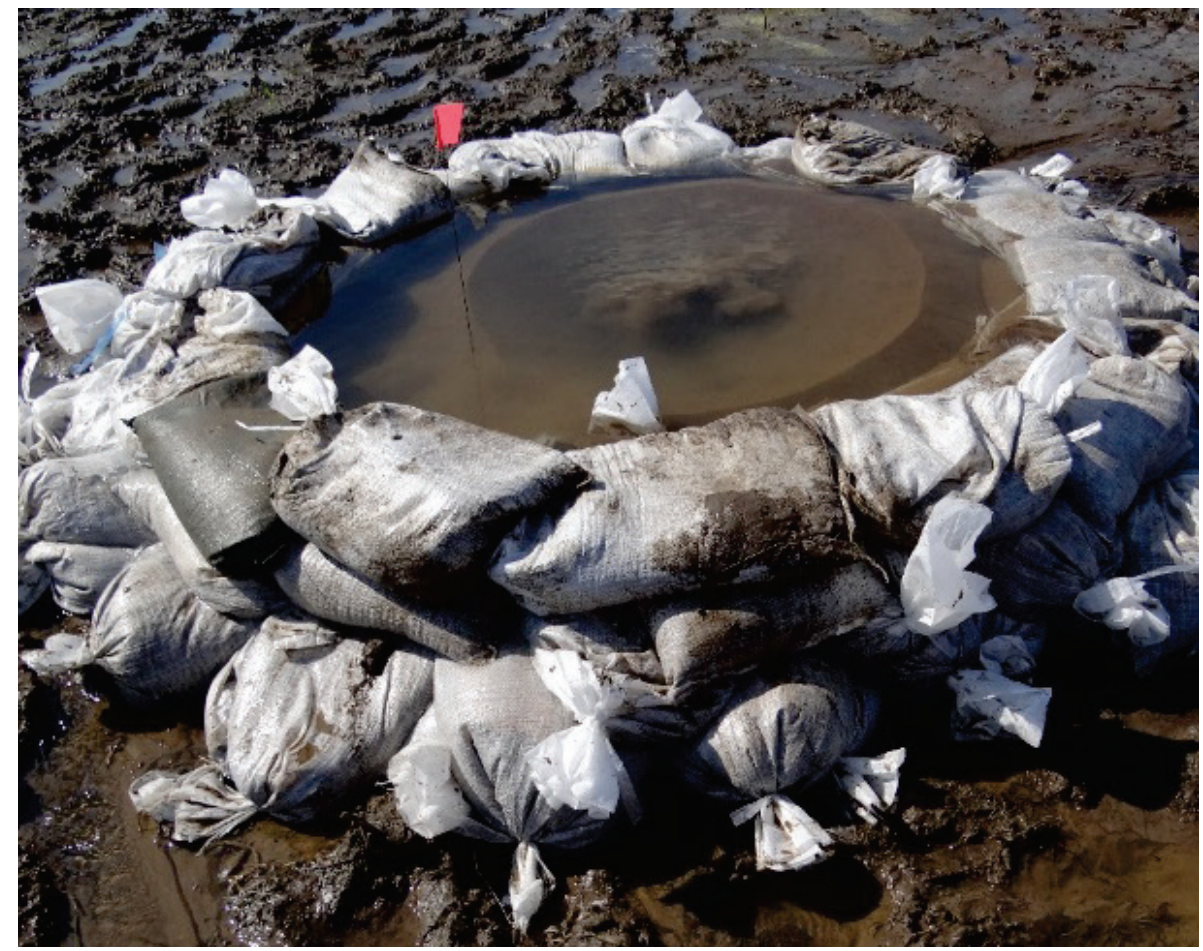

Figure 2. Photograph of typical sandbag ring used to control sand boils.

\section{THE SAND BOIL GENERATOR}

A device capable of generating full-scale sand boils in a controlled environment has been developed. This device allows researchers to duplicate sand boil conditions with control over a wide range of variables, including hydraulic gradient, flow rate, grain size, throat diameter, and the amount of suspended solids, while allowing observers to see and measure the effects of different flood-fighting strategies. A schematic of the device is provided as Figure 3.

The device consists of an elevated reservoir connected to an instrumented, vertical column used to simulate the throat of a sand boil through an impermeable confining layer. A sand hopper is connected to the base of the column that is capable of injecting sand into the vertical column at controlled rates. The sand is injected into the column to simulate the sand that would be transported to the boil by the erosion channels in the foundation. The sand is then transported vertically through the column and deposited on a level surface resulting in the formation of a sand boil. Pressure measurement ports spaced throughout the vertical column lead to a manometer board that displays pressures at different depths along the throat. The water surface in the discharge area is regulated by a series of weirs that control the level of sand boil submersion and determine the flow rate through the boil. The outflow from the system is captured in a tank and recirculated. Photographs of the completed sand boil generator and an active sand boil created in the device are shown in Figure 4. 


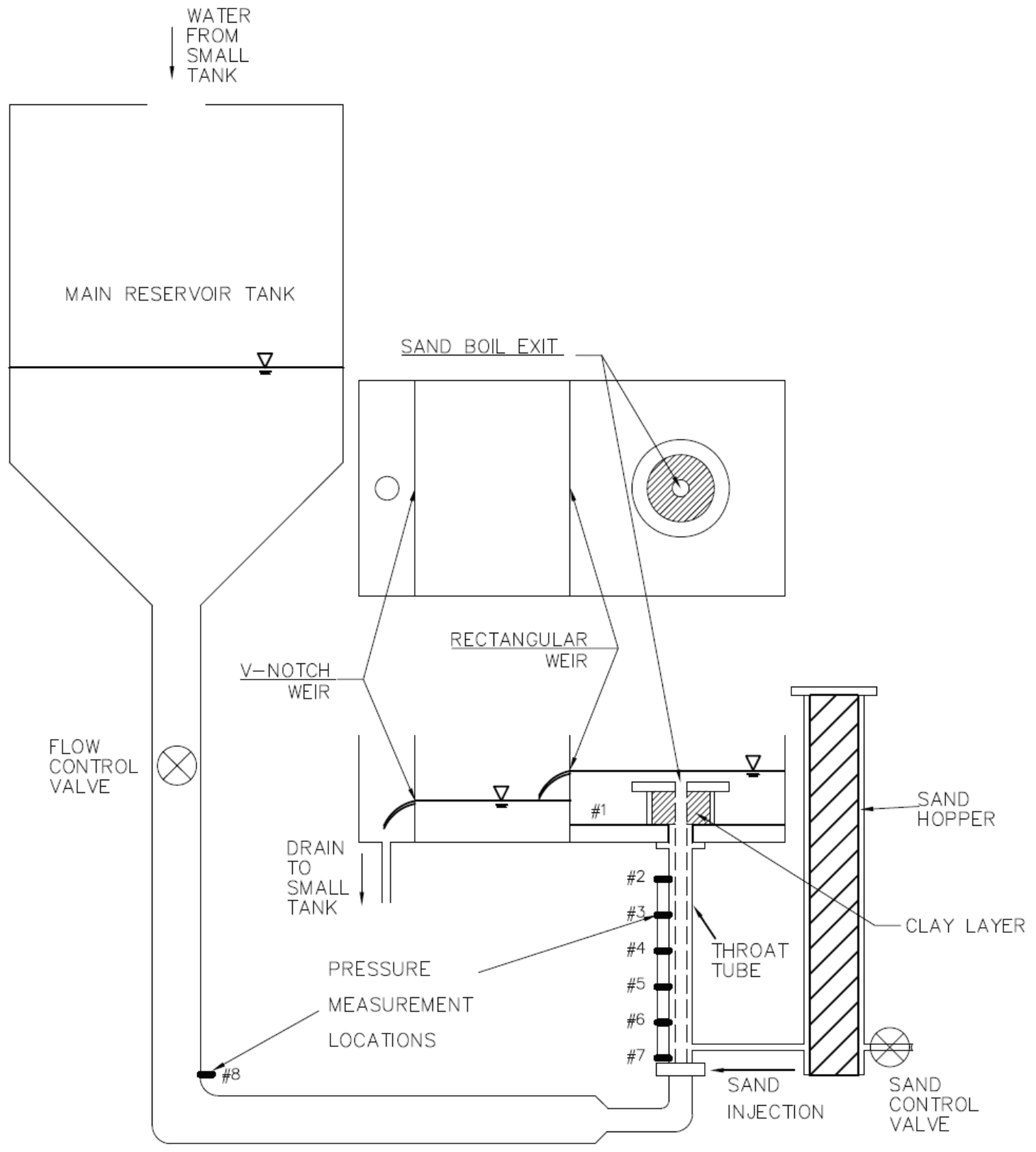

Figure 3. Schematic of the sand boil generator. 


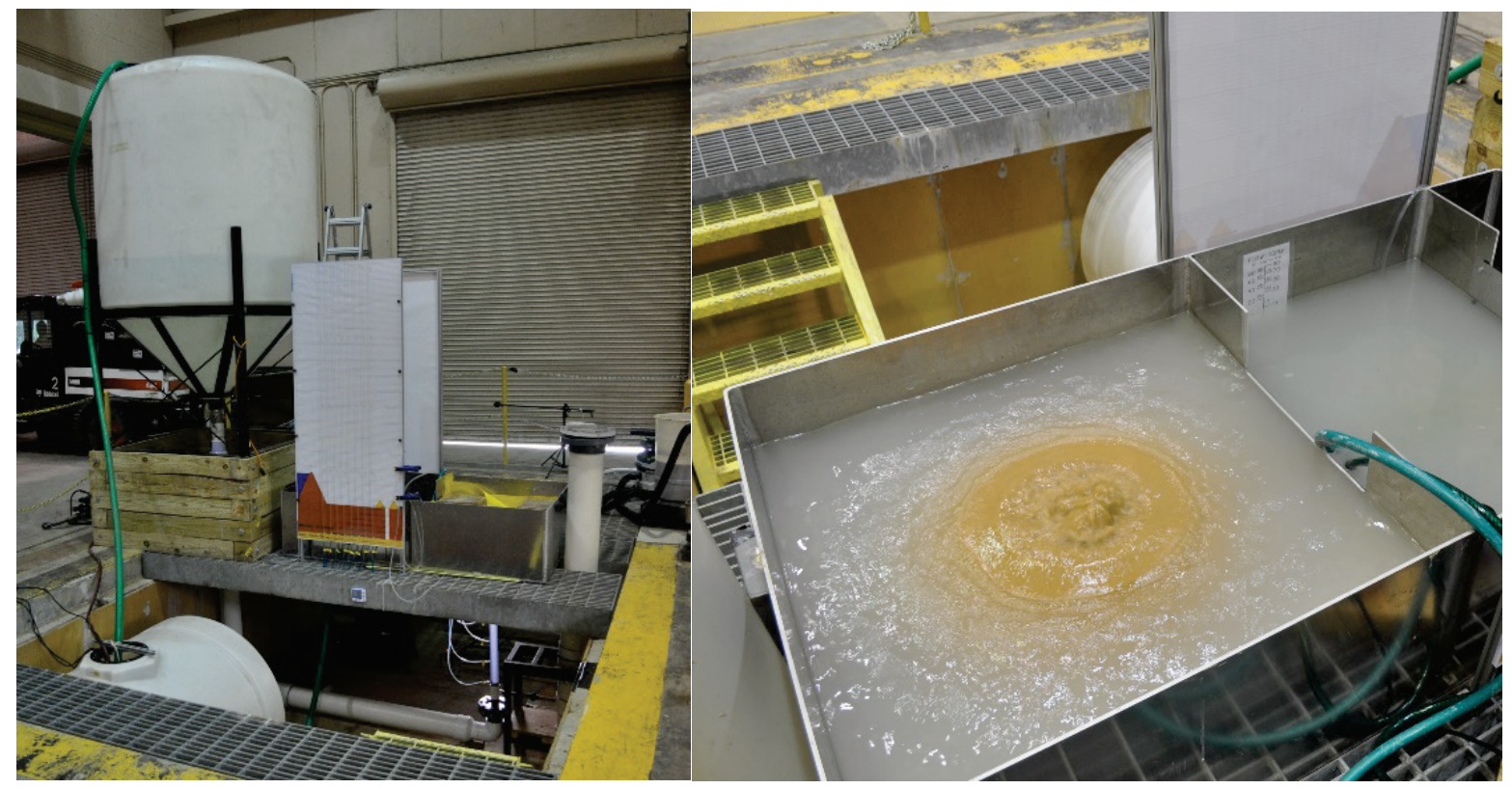

Figure 4. Overview of the sand boil generator (left) and an active sand boil (right).

\section{STUDY OF SOIL AND FLUID FLOW}

Study of active sand boils in the field has led to the development of a hydraulic theory that describes the anticipated pressure changes (head losses) through a sand boil as a function of geometry, discharge, and grain size (Robbins et al. 2018). The sand boil generator was used to evaluate the assumptions made in the theoretical model described in Robbins et al. The following sections outline the test procedure and results obtained from initial tests conducted during 2018. Further tests were planned to perform a systematic evaluation of various types of filter materials for controlling sand boil development.

\section{Test procedure}

1. Prior to beginning, the hole diameter through the clay layer was checked to ensure it matches the inside diameter of the sand boil throat pipe. The clay may need to be reshaped if deformed.

2. Clamps were placed on the clear lid of the sand hopper to seal. Originally, stainless steel nuts and bolts were used to hold the lid in place; however, it was found that the stainless steel nuts and bolts have a tendency to bind. The bolts were replaced with clamps to allow easy reloading of the hopper with clean sand upon completion of testing.

3. An initial flow rate through the device was set by adjusting the valve on the head reservoir. The flow rate chart for the v-notch weir provides approximate values of the flow rate.

4. Prior to injecting any sand, the time, flow rate, and initial manometer levels were recorded to establish the base conditions for hydraulic losses in the system without sand. The datum for head measurements was taken as the bottom of the impervious top stratum (Figure 5).

5. The sand injector valve was then opened just enough to move sand from the hopper into the throat tube. This initiated a steady, continuous stream of sand into the sand boil throat. 
6. The time, flow rate, and manometer levels were recorded during active erosion and transport.

7. Conditions were monitored until the sand hopper was depleted. The sand injector valve was then closed, and the system was allowed to sit until steady, stable conditions were obtained.

8. The time, flow rate, and manometer levels were then recorded again as the "reworking sand" entry. This corresponded to conditions with a stable sand boil cone size with sand churning in the boil. The sand boil throat tube was clear of sand for the flow rates reported.

9. The dimensions of the sand cone were recorded. At a minimum, measurements of the width $(W)$, height (h), exterior and interior slope lengths $\left(\mathrm{L}_{e}\right.$ and $\left.\mathrm{L}_{\mathrm{i}}\right)$, and angles $(\beta$ and $\alpha)$ of the deposited sand slopes were obtained.

10. The sand cone was physically removed from the throat entrance before closing the supply valve to avoid filling the throat with sand upon shut down. The valve was then closed, and the test was terminated.

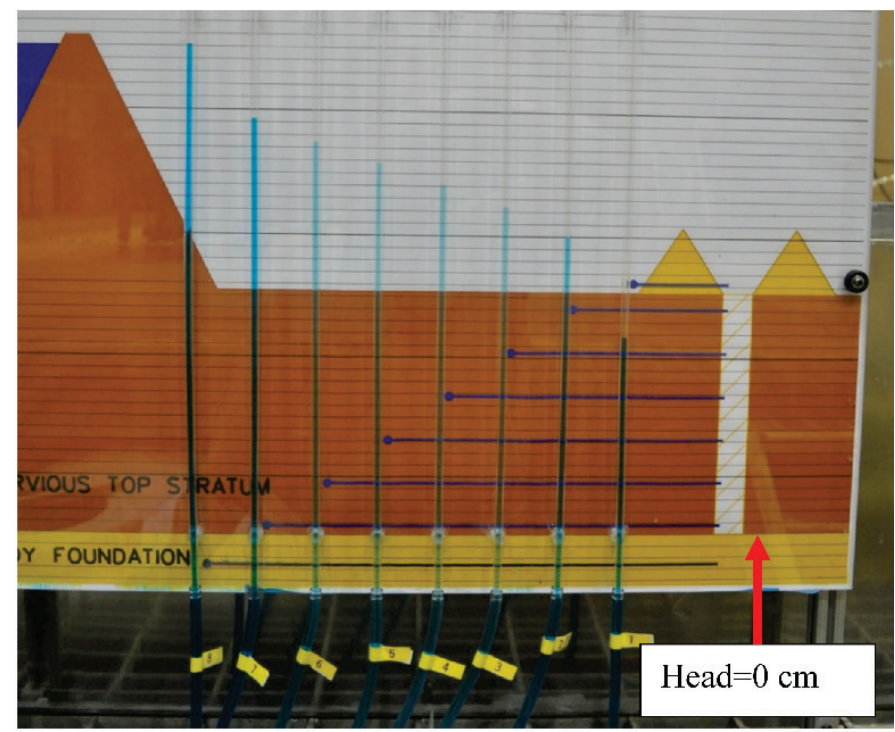

Figure 5. Manometer board with vertical datum labeled.

RESULTS AND OBSERVATIONS FROM INITIAL TESTS. Excess head (head above the tailwater elevation) was plotted relative to the depth below the tailwater for each series of measurements at flow rates $(\mathrm{Q})$ of $1,5,7$, and $10 \mathrm{gpm}$. A flow rate of $1 \mathrm{gpm}$ did not have adequate velocity to transport the sand, and there was little difference between excess head measurements for $\mathrm{Q}=5$ and $7 \mathrm{gpm}$. Therefore, results from $\mathrm{Q}=5$ and $10 \mathrm{gpm}$ were the focus of initial tests. A sand referred to as $40-70$ sand with a $\mathrm{D}_{50}$ of $0.3 \mathrm{~mm}$ was used. Excess head, sand cone width, and sand cone height were compared to values predicted by the theory described in Robbins et al. (2018). 
Differences in the theoretical and measured sand cone dimensions were studied by increasing tailwater elevation to determine if the sand cone height is limited by this variable. Results indicate that the sand cone height was not being limited by the lower tailwater, but instead was limited by the quantity of sand injected. These dimensions are important with regards to validating the assumptions in the theory regarding the height of the sand boil cone. Excess head measurements compared favorably with the theory for $\mathrm{Q}=10 \mathrm{gpm}$ (Figure 6).

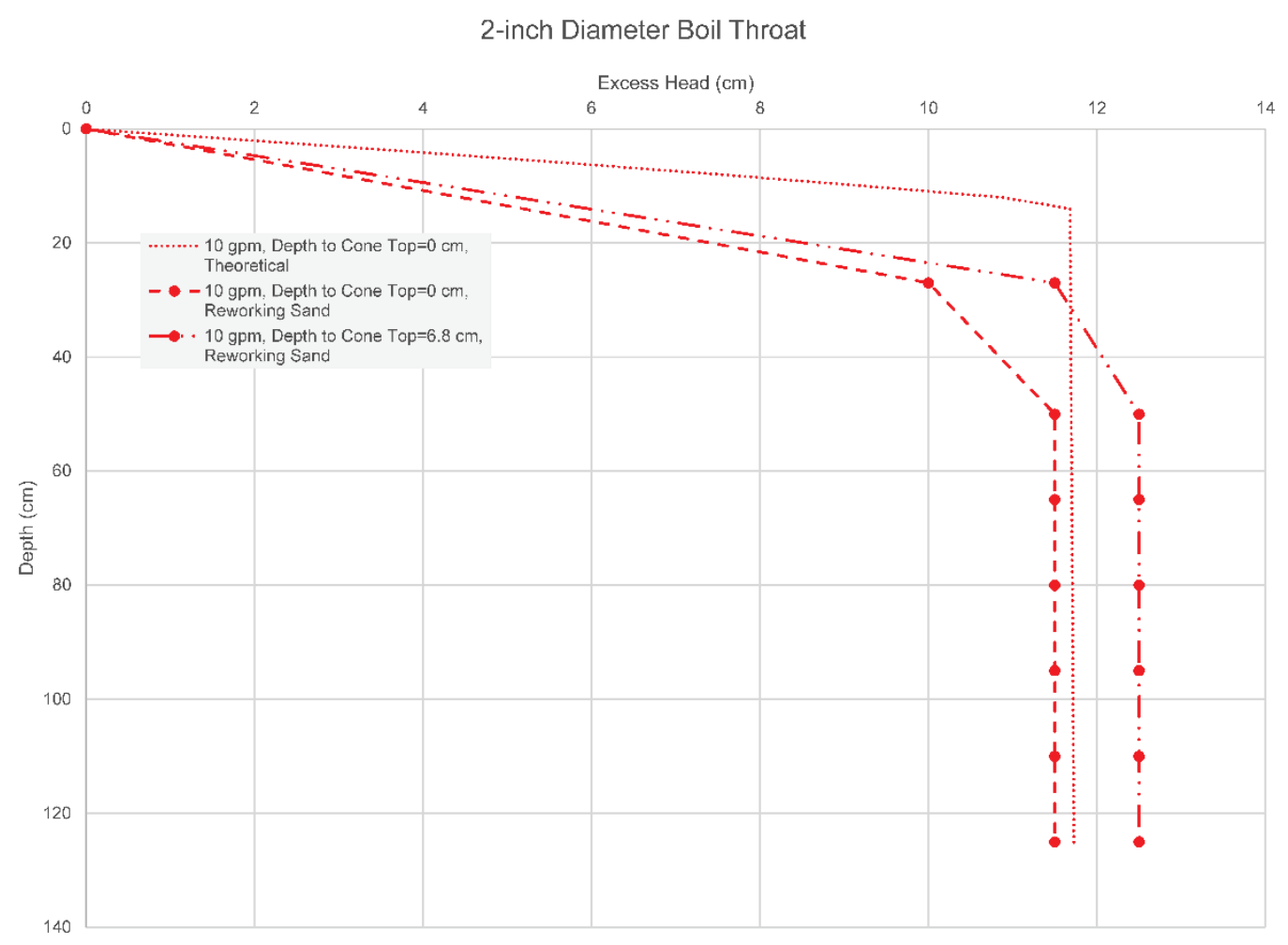

Figure 6. Excess head vs. depth for $\mathrm{Q}=10 \mathrm{gpm}$.

At $\mathrm{Q}=5$ gpm, additional excess head measurements were made within and above the sand cone elevations. Results are plotted in Figure 7. This demonstrates that when the tailwater is above the sand cone, excess head will be dissipated before the depth is zero. A theoretical assumption is that tailwater elevation is equal to the top of the sand cone, so excess head does not decrease to zero until the depth is zero. Also apparent is that the measured zone of head loss extends deeper than predicted by theory for these tests, as indicated by the depth at which the excess head remains nearly constant. This discrepancy will be further explored in future tests. 


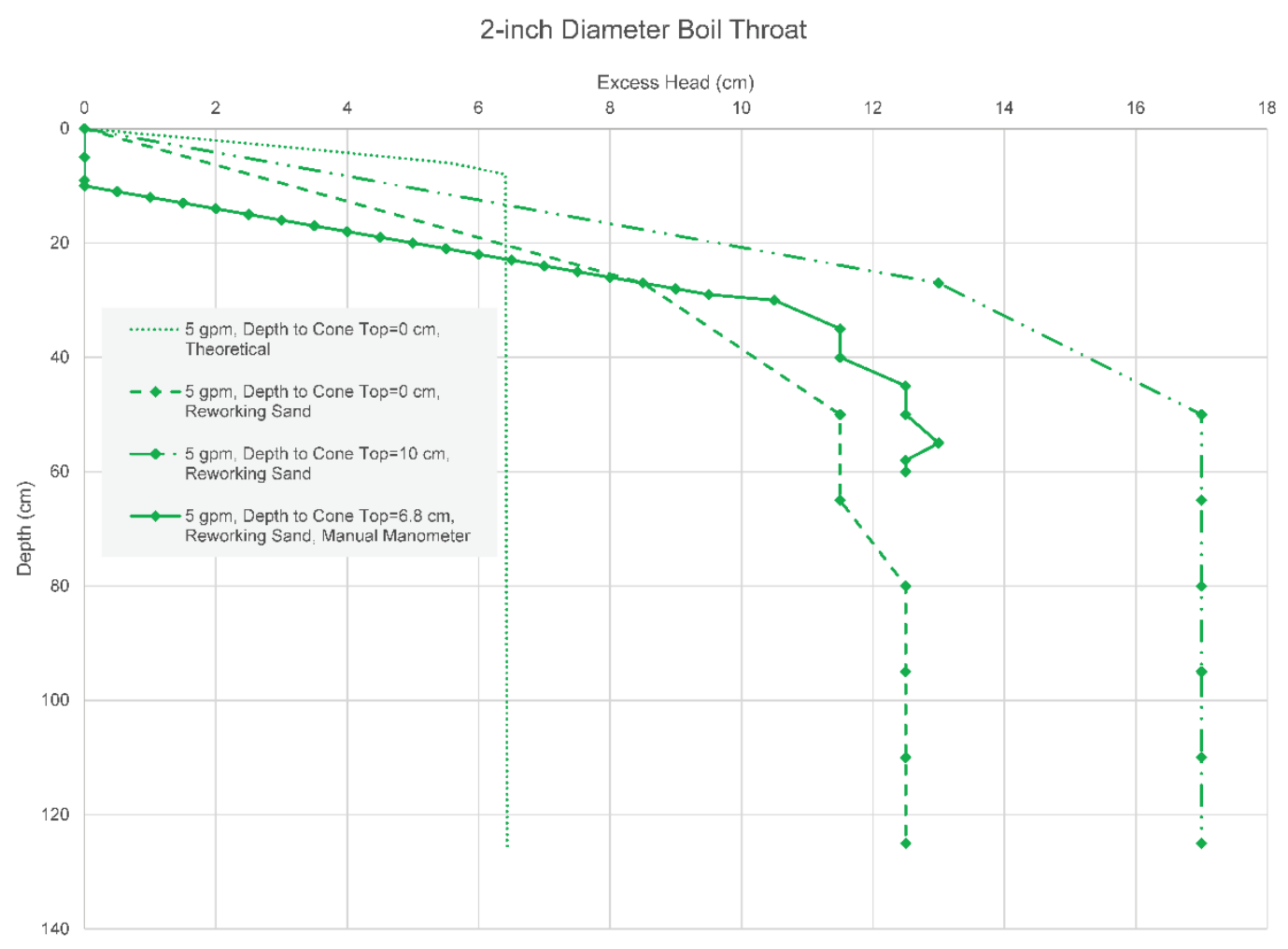

Figure 7. Excess head vs. depth for $Q=5 \mathrm{gpm}$.

\section{CONCLUSIONS}

The U.S. Army Corps of Engineers has effectively managed risks associated with BEP through active flood fighting of sand boils along levees during flood events, most commonly through labor-intensive placement of sandbags. Flood-fighting operations can potentially be made more efficient and effective by developing alternate means of controlling sand boils. This paper describes a sand boil laboratory device that was developed for testing potential control measures in a laboratory setting and presents initial results obtained from testing. Further testing of innovative flood-fighting measures was continued in 2019.

Funding for this work was provided by the U.S. Army Corps of Engineers Flood Risk Management Research and Development program. Permission to publish was granted by Director, Geotechnical and Structures Laboratory.

\section{REFERENCES}

Robbins, B. A, Stephens, I. J., van Beek, V., Koelewijn, A., and Bezuijen, A. 2018. Field measurements of sand boil hydraulics. Géotechnique doi:10.1680/jgeot.18.P.151. 